\title{
An Experiential Learning Activity to Promote Skill DeVELOPMENT In First Year EngineERING STUdents
}

\author{
W. Bishop \\ Department of Electrical and \\ Computer Engineering \\ University of Waterloo \\ Waterloo, ON, N2L 3G1
}

A. Hurst and B. Mantin

\author{
Department of \\ Management Sciences \\ University of Waterloo \\ Waterloo, ON, N2L 3G1
}

\author{
S. Bedi
}

wdbishop@uwaterloo.ca adahurst@uwaterloo.ca and bmantin@uwaterloo.ca sanjeev.bedi@uwaterloo.ca

\begin{abstract}
This paper describes an experiential learning activity to promote skill development in first year engineering students. The exercise involves the assembly of a remote-control car using readily available part kits. Students work in small teams under the mentorship of experienced faculty members from a variety of engineering backgrounds. The goal of the exercise is to introduce engineering design into first year engineering by providing students with an engaging, hands-on experience. The exercise is one of several new activities being incorporated into the Ideas Clinic Experience for engineering students at the University of Waterloo.
\end{abstract}

Keywords: Ideas Clinic Experience, experiential learning, first year engineering, engineering design and assembly, model visualization, graduate attributes, and expected learning outcomes.

\section{INTRODUCTION}

Experiential learning activities are an essential part of a successful engineering undergraduate program. An Ideas Clinic Experience uses experiential learning in a way that delivers both horizontal integration (i.e., integration across engineering disciplines) and vertical integration (i.e., integration across different cohorts of students). Students face design challenges outside their discipline of expertise with the help of mentors from other disciplines. Thus, an Ideas Clinic Experience prepares students to work effectively in a multi-disciplinary setting, a graduate attribute of the Canadian Engineering Accreditation Board [1] as well as an expected outcome of all undergraduate programs in the Province of Ontario [2].

In the "Engineering Design Assembly Exercise", students work in teams of four to design and construct a remote-control car in less than two hours. Each team is provided with the part kits (gearbox, remote-control box, vehicle, and wheels) and tools (screwdriver, side cutters, and a nail file) necessary to complete the design. Teams are given minimal instructions beyond those provided by the part kits. Teams must analyze the kits, visualize how they are to be assembled, and then use the tools provided to complete the assembly. Finally, teams must test their designs and make improvements as required. At the end of the activity, teams retain the vehicles so that they may continue their learning outside of the classroom.

The Engineering Design Assembly Exercise was the focus of two pilot projects conducted in the Fall of 2014. The first pilot project examined the use of the activity in a first year Management Engineering course (MSCI 100) offered to approximately 80 students. The second pilot project examined the use of the activity in a first year Electrical and Computer Engineering course (ECE 100A) with approximately 60 students participating. To introduce some vertical integration, upper-year students were also invited to participate in the second pilot project.

The experiences of both pilot projects are summarized in this paper. A summary of the part kits and tools necessary to replicate the activity in an academic setting is provided. The steps necessary for the successful completion of the activity are identified. The assembly process is explained along with a discussion of the points of significant reflection. Finally, a few observations based on our initial experiences are provided. Feedback obtained through student surveys is briefly discussed. 


\section{BACKGROUND ON STUDENT-ENGAGED LEARNING}

One of the main shifts in engineering education has been the application of educational, learning, and social-behavioural sciences research [3]. Two of the most influential educational and learning theories are Experiential Learning Theory (ELT) [4] and ProblemBased Learning (PBL) [5].

ELT defines learning and the resulting creation of knowledge as a process of grasping and transforming experience. The former is accomplished through Concrete Experience (CE) and Abstract Conceptualization (AC), whereas the latter is a process of Reflective Observation (RO) and Active Experimentation (AE). The process of learning passes through all the different steps, in a repeating experiencing-reflecting-thinkingacting cycle that is dependent on the object and circumstances of learning [4].

According to PBL theory, learning occurs best when students work together to solve a (realistic) problem. The problem, or trigger, offers a memorable context and engages students in a multi-step process of retrieving prior knowledge and identifying new areas needing learning [6].

While traditionally the instructor has been thought of as an imparter of knowledge, when the goal becomes to engage students with learning, the instructor's role becomes that of the creator of opportunities and experiences that facilitate learning [6]. Thus, to promote experiential learning in the classroom, it is the responsibility of the instructor to create learning spaces that enable students to experience [7].

Students have a critical role to play. While traditionally learning has been looked at as an individual endeavor, experiential and problem-based learning requires a communal approach. Engaging learning opportunities must be cooperative; they must require high task interdependence and individual and group accountability [6].

\subsection{The Ideas Clinic Experience}

Cooperative/experiential learning has been put into practice in engineering education in different contexts and through various means. Implementations vary in scope and impact, but of particular interest are largescale, faculty-wide initiatives.

For example, the Integrated Teaching and Learning (ITL) program at University of Colorado was conceived as a curriculum-based concept that was to involve the entire undergraduate engineering student body in a multi-disciplinary, integrated curriculum that included significant design, hands-on, and multidisciplinary project components [8]. A central component of ITL was the ITL Laboratory a non-traditional facility that supported flexible, visual, and interactive hands-on engineering activities that engaged students throughout the curriculum [8].

The Ideas Clinic at the University of Waterloo is a similar initiative that was launched in 2013 with the goal of integrating the engineering curriculum across disciplines, courses, and student cohorts. This facultywide, cross-departmental effort aims to supplement two existing pillars of the Waterloo engineering education: in-class (traditional) instruction and industrybased co-operative education. Most Ideas Clinic activities will eventually be held in a state-of-the-art space in a new engineering building to be constructed soon.

Clinic activities embody the principles of experiential and problem-based learning. Students work in groups to investigate and solve authentic, openended problems in a hands-on and immersive context. Generally, the activities do not neatly fall under a specific course. Instead, the activities present students with problems and contexts that span courses and disciplines, just like "real life". They provide students with challenging, but ultimately rewarding experiences, that promote not only technical skills but also valuable non-technical skills such as teamwork, communication, and problem solving.

\subsection{Examples of Ideas Clinic Activities}

Beginning in Fall 2014, a growing list of activities have been developed, piloted, and refined. Examples of these activities include:

- A Coffee Maker Dissection Activity challenged students to disassemble, inspect, and come to understand the workings of a common household machine. This activity was modelled after a similar activity involving the dissection of an internal combustion engine.

- A Keychain Machining Activity taught students to machine and build a small keychain. This confidence-building experience introduced students to the Student Machine Shop [9].

- A Brushless DC Motor Activity instructed students on winding, building, and testing an electric motor.

- A Repair Café provided students with opportunities to repair a variety of common objects such as keyboards, CD-ROMs, cooling fans, etc.. 


\section{THE ENGINEERING DESIGN ASSEMBLY EXERCISE}

In developing the Engineering Design Assembly Exercise, the goal was to provide students with a handson assembly activity that was fun and educational. The exercise was designed to expose first-year students to reading instructions, visualizing a design, and working with simple tools. Assembly of a remote-control car was chosen for the following reasons:

1) Suitable model kits were readily available.

2) Completion of the design requires fundamental electrical and mechanical engineering skills.

3) The entire design can be built by a team of students in less than 2 hours.

4) The chassis allows for future extensions.

Figure 11 shows an assembled remote-control car. The chassis consists of a board that allows for easy modification. Students may elect to build either a front wheel drive vehicle or a rear wheel drive vehicle. The joystick provides additional control wires that may be used to drive accessories. Simple mechanical connections avoid the need for soldering the control wires. The kits produce a simple yet functional design.

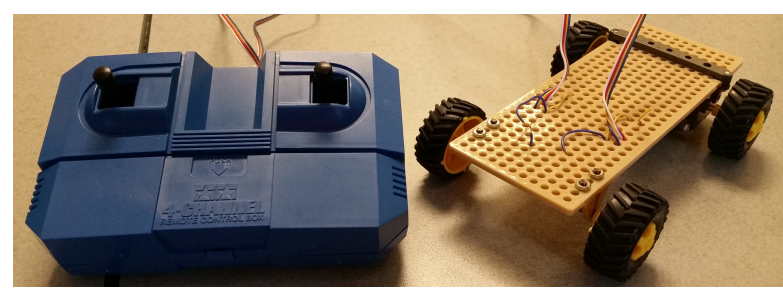

Figure 1. An Assembled Remote-Control Car

\subsection{Supplies}

The part kits and supplies used in the Engineering Design Assembly Exercise are summarized in Table 1 . The total cost for a single set of supplies was $\$ 55.79$ plus applicable taxes. After applicable discounts, the cost for consumables was less than $\$ 12$ per student.

Table 1. Itemized List of Supplies

\begin{tabular}{||l|c|c||}
\hline \hline \multicolumn{1}{|c|}{ Supply } & $\begin{array}{c}\text { Manufacturer } \\
\text { Part } \\
\text { Number }\end{array}$ & $\begin{array}{c}\text { Approximate } \\
\text { Retail } \\
\text { Price }\end{array}$ \\
\hline \hline 4 Channel Remote Control Box & Tamiya 70106 & $\$ 22.95$ \\
\hline Double Gearbox Left/Right Independent 4-Speed & Tamiya 70168 & $\$ 13.95$ \\
\hline Universal Plate Set & Tamiya 70098 & $\$ 7.95$ \\
\hline Truck Tire Set (36 mm) & Tamiya 70101 & $\$ 5.95$ \\
\hline 2 Alkaline D Batteries & Duracell MN1300 & $\$ 4.99$ \\
\hline \hline
\end{tabular}

CEEA15; Paper 104

McMaster University; May 31 - June 3, 2015

\subsection{Tools}

The hand tools used in the Engineering Design Assembly Exercise are summarized in Table 2. It should be noted that students are not provided with the exact set of tools recommended by the manufacturer of the kits. Instead of using a utility knife for cutting plastic parts, the instructors felt that the use of high leverage diagonal pliers would be safer. For ease of use, sandpaper was replaced with the use of an emery board.

Table 2. Itemized List of Tools

\begin{tabular}{||l|c|c||}
\hline \hline \multicolumn{1}{|c|}{ Tool } & $\begin{array}{c}\text { Manufacturer } \\
\text { Part } \\
\text { Number }\end{array}$ & $\begin{array}{c}\text { Approximate } \\
\text { Retail } \\
\text { Price }\end{array}$ \\
\hline \hline Mastercraft Maximum 6-in High Leverage Diagonal Pliers & $58-4303-0$ & $\$ 17.99$ \\
\hline Mastercraft Maximum Phillips Screwdriver & $57-3672-8$ & $\$ 6.29$ \\
\hline Pharmasave Emery Boards 4.5 inch (9 Pack) & 58030005830 & $\$ 1.99$ \\
\hline \hline
\end{tabular}

\section{MANAGEMENT ENGINEERING PILOT PROJECT}

The first pilot of this activity was held for Management Engineering (MGTE) students in MSCI 100, a foundational concepts course. The activity was scheduled for the 7 th week of the term, two weeks prior to a planned class visit to the Toyota plant in Cambridge, Ontario. The connection between the activity and the Toyota field trip was further developed in the 8th week of the term, when a retired VP Manufacturing from Toyota gave a guest lecture to the class on managing processes and the Toyota Production System (TPS).

\subsection{Expected Learning Outcomes}

The expected learning outcomes were the following:

- Experience the difficulties with production line layout and balancing

- Understand the challenges of manufacturing

- Work collaboratively in a team setting

- Work hands-on using common tools (screwdrivers, cutters, etc.)

- Manage uncertainty and learn to understand vague/incomplete assembly instructions

\subsection{Additional Resources}

The activity was held in the regular classroom for MSCI 100, which is a traditional, lecture-style room, equipped with long rows of fixed desks and chairs. It was led and facilitated by the course instructor (the third co-author of this paper). To provide assistance 
and observations, another faculty member in the Department of Management Sciences (the second coauthor of this paper) and two course TAs were also in attendance.

In addition, a custom-made race track was brought into the room. At the completion of the activity, students were expected to use the track to test the performance of the assembled car and demonstrate the differences in performance between the different configurations (such as ease of manoeuvering, speed, and ability to climb slopes).

\subsection{Activity Context and Instructions Pro- vided to Students}

At the beginning of class, the course instructor held a brief introductory presentation to provide context and link the activity to the wider course topics. The discussion began with the announcement of the Toyota trip, where students would be able to observe a real factory line. The discussion also touched briefly on the importance of safety, operator training, and planning.

Next, the discussion challenged students to consider the complexity of the car manufacturing industry. In particular, students were provided some impactful statistics such as the large number of components of an average car (about 30,000), the number of cars produced (e.g., 19 million/year in China alone), and the length of time it takes to produce a single car (approximately 18 hours).

Students were then asked to form teams of four to assemble the remote-control cars using the kits and tools provided. Each team was randomly assigned one of the four gearbox configurations. This ensured that all configurations would be attempted.

Before students began the assembly, the instructor facilitated a brief discussion around safety, including the safety of using the cutters and the batteries (although the latter were not provided to students until the testing phase).

Students were provided with the following instructions on how to best build the remote-control car:

- Identify and plan the sequence of steps and tasks required to assemble the car.

- Assign the different tasks to team members.

- Pay attention to the distribution of work.

- Pay attention to the layout, instructions, and the sequence of assembly.

- Before starting the assembly, guess the time required.

- Pay attention to what happens during the process.

- Finish quickly but maintain quality!
One of the assembly kits had already been assembled by the two faculty members in attendance. The process had taken approximately 45 minutes, thus it was estimated that 60 minutes would be a sufficient amount of time for a team of 4 students. The finished remote-control car was available at the front of the classroom as a reference for students.

Although the activity involved assembly of model kits, it was nevertheless a design activity. Specifically, the management engineering design challenges presented by this activity included planning the assembly process, identifying tasks that could be completed in parallel, and assigning members to tasks.

\subsection{Classroom Observations}

The activity had been planned such that it would take 2 hours of class time: 20 minutes for a preactivity discussion, 1 hour for assembly, 20 minutes for testing, and 20 minutes for a post-activity discussion. However, it quickly became apparent that 1 hour was not sufficient time for most teams to complete the assembly. The activity length was extended such that students were given almost 2 hours for the assembly portion alone. Yet, even with the extended length, only about half of the teams completed the assembly and were able to test their cars on the track. There were various reasons for this:

- Not all assembly configurations were equally difficult to assemble. Some configurations were trickier to put together.

- Some teams were successful in planning and implementing an efficient division of labour, such that tasks were completed simultaneously by different team members. Other teams planned the assembly such that tasks needed to be completed in a sequential manner; as a result, team members were sitting idle.

- Some of the teams had difficulty reading and understanding the instructions. Some misread or misunderstood the steps.

- Many students lacked prior experience with model kits. While some students were well versed in this type of activity, others surprisingly expressed that they had never done anything like this before. One student in the latter group was quoted as saying "This is my greatest achievement!"

In general, student engagement in the activity varied dramatically between and within the teams. While some students/teams were actively engaged, some seemed detached and disinterested.

A final note was made with regards to the space in which the activity was held. Unfortunately, the 
classroom was not adequate for this type of activity. Small pieces would fall between the rows of desks and were difficult to retrieve. The fixed desks and chairs made group work difficult because students could not easily arrange themselves in a circle formation.

\subsection{Post-Activity Reflection}

The instructor postponed the post-activity reflection due to the extension of the activity. Students had an opportunity to reflect on the experience and draw connections to course topics. Students were challenged to consider the role of management in the planning and design of an assembly process. The discussion examined the following themes:

- Discovering Bottlenecks: Process analysis was covered in the course so students were expected to identify bottlenecks. In this exercise, the bottleneck was often the screwdriver (as teams only had one) or the completion of the main assembly.

- Planning and Line Balancing: Relating to process analysis, students were challenged to find ways to address issues faced in the assembly process.

- Scaling Up: The class activity demonstrated a "simple" assembly that could be completed within an hour. Real assemblies are far more complex. This was an open-ended discussion in preparation for the Toyota plant visit.

- Introducing Flexibility: Students were encouraged to suggest ways to facilitate flexibility in production. Flexibility was observed at the Toyota plant.

- Managing Uncertainty: Students were challenged to think about demand uncertainty and consider issues pertaining to inventory.

\section{ELECTRICAL AND COMPUTER ENGINEERING PILOT PROJECT}

For the Electrical and Computer Engineering (ECE) pilot project, the Engineering Design Assembly Exercise was implemented differently. Some alterations were in response to student feedback from the first pilot project and others were necessary to achieve the expected learning outcomes.

\subsection{Expected Learning Outcomes}

For the ECE pilot project, the expected learning outcomes were the following:

- Collaborate effectively with team members to complete a task.

- Identify parts of an engineering model.
- Visualize how parts of an engineering model fit together.

- Assemble an engineering model given a set of instructions and a set of parts.

- Synthesize alternatives to enhance the functionality of a design.

A strong emphasis was placed on identifying parts, visualizing how the parts fit together, and following instructions. These expected learning outcomes are often poorly addressed by first year ECE courses at the University of Waterloo.

\subsection{Student Participation}

For the ECE pilot project, the exercise was an optional activity performed outside of normally scheduled class hours. Student performance was not formally assessed. Despite the fact that the activity was not graded, student participation was quite high. Approximately $20 \%$ of the first year class of ECE students participated in the pilot project held on a Friday night. In addition, a team of third year students participated in the pilot project. All of the students who participated had a clear interest in participating in the exercise.

\subsection{Activity Location}

The exercise was conducted in the WEEF (Waterloo Engineering Endowment Fund) Lab at the University of Waterloo to provide adequate room to examine, assemble, and test the designs. This environment turned out to be a highly suitable location for student groups to work productively. Students had access to computers to seek out additional information. They also had access to large table space to assemble their designs and floor space to test their designs. This lab environment was superior to the classroom environment used in the first pilot project.

\subsection{Instructions Provided to Students}

ECE student groups were provided with ten instructions designed to guide teams through the process of building a remote-control car. These instructions were the following:

- Select one member of your team to obtain the four part kits required for the exercise.

- Select one member of your team to sign out a set of tools for the exercise.

- As a team, identify potential safety hazards.

- As a team, review the instructions provided in each kit.

-5 of $6-$ 
- Divide into two smaller teams of two members each.

- Team 1 constructs the gearbox (Option B works well); Team 2 constructs the joystick.

- Select one member of your team to mount the gearbox on the universal plate set.

- Select one member of your team to connect the joystick to the gearbox.

- Select one member of your team to add the wheels to the vehicle.

- As a team, test and re-design the vehicle.

\subsection{Mentoring Provided to Students}

Throughout the activity, mentorship was provided by faculty members from three different disciplines (ECE, MME, and MGTE). This diversity of mentorship ensured that students evaluated the designs from different perspectives. At key points in the assembly process, students were asked to reflect on a particular aspect of the design. This reflection greatly enhanced the learning experience. The student-to-faculty ratio was smaller for this pilot project. For every 15 students, there was a faculty mentor. This approach to mentorship greatly improved the delivery of the exercise.

\section{OBSERVATIONS}

Both pilot projects were successful. Students were surveyed on their perception of the activity. They were asked to indicate their level of agreement with the following statements:

- I found this activity to be fun.

- I found this activity to be relevant to my engineering education.

- I have a greater understanding of the hazards and risks in engineering design.

- I recommend the use of hands-on activities such as this one.

The student survey was conducted from the perspective of process improvement so the results cannot be presented in detail here. However, it is fair to say that the survey results overwhelmingly supported the use of the exercise in future offerings of the courses.

Another key observation was that the participation of upper-year students in the ECE offering of the activity seemed to have a positive effect upon the completion rate of the exercise. Perhaps students had a different perception of the exercise due to the presence of upper-year students or perhaps students wished to demonstrate their skills in the presence of upper-year students. The student teams demonstrated a strong desire to complete the design. $100 \%$ of the teams assembled a working design in the second pilot project.

\section{CONCLUSIONS}

Both pilot projects provided insight into the use of the Engineering Design Assembly Exercise. Clearly, the exercise itself is not as important as the way it is delivered to students. Both pilot projects demonstrate that when delivered properly, a seemingly simple exercise can provide a highly valuable learning experience to students.

\section{References}

[1] CEAB. (2011) Accreditation Criteria and Procedures 2011. Canadian Engineering Accreditation Board. [Online]. Available: http://www.engineerscanada.ca/ files/w_Accreditation_Criteria_Procedures_2011.pdf

[2] (2012) Program Review and Accreditation - Background. Centre for Teaching Excellence, University of Waterloo. [Online]. Available: http://cte.uwaterloo.ca/teaching_ resources/OCAV/index.html

[3] J. Froyd, P. Wankat, and K. Smith, "Five major shifts in 100 years of engineering education," Proceedings of the IEEE, vol. 100, no. Special Centennial Issue, pp. 13441360, May 2012.

[4] D. Kolb, Experiential Learning: Experience as the Source of Learning and Development. Pearson FT Press, December 2014.

[5] D. E. Allen, R. S. Donham, and S. A. Bernhardt, "Problem-based learning," New Directions for Teaching and Learning, vol. 2011, no. 128, pp. 21-29, 2011. [Online]. Available: http://dx.doi.org/10.1002/tl.465

[6] K. A. Smith, S. D. Sheppard, D. W. Johnson, and R. T. Johnson, "Pedagogies of engagement: Classroombased practices," Journal of Engineering Education, vol. 94, no. 1, pp. 87-101, 2005. [Online]. Available: http://dx.doi.org/10.1002/j.2168-9830.2005.tb00831.x

[7] A. Y. Kolb and D. A. Kolb, "Learning styles and learning spaces: Enhancing experiential learning in higher education," Academy of Management Learning \& Education, vol. 4, no. 2, pp. pp. 193-212, 2005. [Online]. Available: http://www.jstor.org/stable/40214287

[8] L. E. Carlson and J. F. Sullivan, "Hands-on engineering: Learning by doing in the integrated teaching and learning program," International Journal of Engineering Education, pp. 20-31, 1999.

[9] J. Baleshta, "Increasing student practical experience with the hurdle of large class sizes," in Proceedings of the 2014 Canadian Engineering Education Association Conference, Canmore, Alberta, Canada, June 2014. 